\title{
RISKY SEXUAL BEHAVIOR AND STI KNOWLEDGE AMONG SENIOR HIGH SCHOOL STUDENTS IN THE SUNYANI MUNICIPALITY, GHANA
}

\section{Antwi Joseph Barimah1, Mohammed Mohammed Ibrahim², Yaw Boakye Nketiah', Bernard Opoku Amoah", Larry Agyemang55, James Dumba', Helina Gyamea7 ${ }^{7}$, and Daniel Atta-Nyarko ${ }^{8}$}

\author{
College Of Health Yamfo-Ghana \\ Quabenabarimah89@yahoo.com¹, Mimkp2004@yahoo.com², Boakyenana14@gmail.com³, \\ bopokuamoah@gmailcom ${ }^{4}$ Laray0111@gmail.com ${ }^{5}$, dumjames28@gmail.com6, gymeaah@yahoo.com7 , and \\ Daniel.nyarko@ahpc.gov.gh8
}

\section{Copyrights}

Copyright for this article is retained by the author, with first publication rights granted to the journal. This is an open-access article distributed under the terms and conditions of the Creative Commons Attribution license

(http://creativecommons.org/licenses/by/4.0/)

\begin{abstract}
Literature has shown that the knowledge and attitudes of young people regarding STIs such as HIV/AIDS and its prevention still remains an important topic in the lives of these young individuals in respect of their decision making so as to practice safer sex options in order to eschew contracting HIV and other STIs. This descriptive cross-sectional study assessed the risky sexual behaviour associated STI knowledge among senior high school students from the Twene Amanfo Senior High Technical School in the Sunyani municipality. The study deployed a randomized sampling technique in recruiting 250 study participants. Quantitative data stemming from the study were analyzed using SPSS version 25 and data were presented using frequencies as tables and figures. The study found that only $40 \%$ of senior high school students possessed high knowledge on STIs whereas the majority of $60 \%$ had low knowledge on STIs associated with sexual risk behaviours. The study concluded on the note that majority of senior high school students had low knowledge on STIs associated with sexual risk behaviour which is worrying. The study therefore recommends that the Ministry of Education must collaborate with the Ministry of Health in rolling out adolescent health programmes in the Ghana education curriculum largely geared towards sex and STI education. This is essential in increasing students' knowledge level on STIs in order to engender preventive and safe sex practices.
\end{abstract}

Keywords: Sexual behaviour, STI knowledge, students, Ghana

\subsection{INTRODUCTION}

It has been vividly shown in the literature that the knowledge and attitudes of young people regarding STIs such as HIV/AIDS and its prevention still remains an important topic in the lives of these young individuals in respect of their decision making so as to practice safer sex options in order to eschew contracting HIV and other STIs. The youth within the age bracket of 15 to 24 years account for approximately half of global HIV new infections. Among students in senior high schools, a chunk of the population falls within this age bracket of 15-24 years. Young people in this age category mentioned are at a higher risk of contracting STIs especially HIV due to sexual risk behaviours which include the failure to use condom during sexual intercourse, indiscriminately having multiple sexual partners and engaging in sexual intercourse at a very young age which implies early sexual debut (Asante, Doku, \& Osafo, 2016).

A study conducted in the Asian province of Bhutan to examine five characteristics of knowledge on STIs in communities, which included; symptoms, prevention, clinical disease, transmission and complications. It was observed that the average score for knowledge to be $61.6 \%$; $91 \%$ on prevention, $70 \%$ on transmission and $60 \%$ on signs and symptoms. However, poor knowledge scores of $40 \%$ and $47 \%$ were recorded on clinical disease and complications, respectively. The study further showed a statistically significant association between the levels of education and knowledge on STIs. It revealed that study participants whose educational level was high were 


\section{International Journal of Multidisciplinary Studies and Innovative Research \\ Publisher: Catholic University College of Ghana \\ ISSN: 2737-7172 (0), ISSN: 2737-7180 (P) \\ DOI: $10.53075 /$ ljmsirq6547586021 \\ DOI Url: http://doi.org/10.53075/ljmsirq6547586021}

more knowledgeable on STI compared to those with lower educational status (Norbu, Mukhia, \& Tshokey, 2013). Though Norbu and colleagues (2013), in their study found out that higher education level was directly associated with a higher level of knowledge on STI, however, the same study observed that there was no decline in risky sexual behaviours in spite of the high knowledge on STIs.

In a study conducted by Ndjiembi and colleagues (2014) in Libreville-Gabon among senior high school students to assess their knowledge, attitudes and practices towards HIV/AIDS.The study observed that half of the respondents were aware of HIV transmission through sexual intercourse (55.7\%), from mother to child (48.3\%) and through sharing needles or syringes $(51.8 \%)$. About $15.14 \%$ of students had an idea of unsafe practices related to HIV transmission. However, only $25.6 \%$ of the respondents who reported engaging in sexual activities used condoms (Christiane, Roger, Masika, \& Zhang, 2014).There is quite a deficit among Ghanaian adolescents and youth regarding knowledge on HIV and other STIs. Findings from the GDHS (2008) stressed that $98 \%$ of females and $99 \%$ of males were very much aware of the presence of HIV in Ghana. Sadly, this awareness of the dangerous virus has not translated into exclusive knowledge and practising safer sexual behaviours. This is because only $25 \%$ of young Ghanaian women and $33 \%$ of young Ghanaian men aged fifteen to twenty-four (1524) years had a good knowledge f STIs and HIV. This low knowledge level on HIV can spell serious public health doom for HIV/AIDS prevention efforts, especially among adolescents and the youth (Oppong Asante, 2013).

According to the Ghana Demographic and Health Survey (GDHS) 2014, sexually transmitted infections such as HIV/AIDS associated knowledge amongst the Ghanaian youth in the age bracket of fifteen to twenty-four (15-24) elucidates the scale at which younger individuals are indulging in risky sexual behaviours that have a high potentiality to increase their chances of acquiring HIV. The survey additionally found that about $20 \%$ of young Ghanaian females and $27 \%$ of young Ghanaian males have a very good knowledge of HIV/AIDS. In terms of young females aged 15-24 years, knowledge was high among those aged 20-24 (22\%), women who were never married $(22 \%)$, among young women in urban areas $(23 \%)$ and those with a secondary school or higher education $(32 \%)$. Similarly, knowledge of HIV/AIDS was higher among men aged 23-24 years (32\%), never-married young men who have ever had sexual intercourse (30\%), men in urban areas (32\%), and men with secondary or higher education (43\%).

Therefore, this study aimed to assess the risky sexual behaviour associated with STI knowledge among senior high school students in the Sunyani municipality to drive appropriate policies necessary to be tailored along those lines to mitigate the STI canker among these young adolescents.

\subsection{MATERIALS AND METHODS}

\subsection{Research Design}

The study deployed a descriptive cross-sectional survey design to asses students' knowledge level on STI associated with risky sexual behaviours.

\subsection{Sampling Technique and Sample Size}

The study utilized a simple random sampling technique in recruiting 250 students from the Twene Amanfo Senior High Technical School. The sample size computation was done using the Cochran formula at 95\% confidence interval with an assumed prevalence (p) of $20 \%(0.2)$.

\subsection{Data Analysis}

Quantitative data emanating from the study were analyzed using the Statistical Package for the Social Sciences (SPSS version 25). Data was presented using frequencies as tables and figures. 
International Journal of Multidisciplinary Studies and Innovative Research

Publisher: Catholic University College of Ghana

ISSN: 2737-7172 (0), ISSN: 2737-7180 (P)

DOI: $10.53075 /$ ljmsirq6547586021

DOI Url: http://doi.org/10.53075/ljmsirq6547586021

3.0 RESULTS

3.1 Demographic Characteristics of Respondents

Table 1; Socio-Demographic Characteristics of Respondents

\begin{tabular}{|c|c|c|c|}
\hline Variable (s) & Category & Frequency $(\mathrm{N}=250)$ & Percent (\%) \\
\hline \multirow[t]{3}{*}{ Age Group } & $12-15$ years & 49 & 19.6 \\
\hline & 16-19 years & 136 & 54.4 \\
\hline & Above 19 years & 65 & 26.0 \\
\hline \multirow[t]{2}{*}{ Sex } & Male & 145 & 58.0 \\
\hline & Female & 105 & 42.0 \\
\hline \multirow[t]{3}{*}{ Religion } & Christianity & 200 & 80 \\
\hline & Islam & 46 & 18.4 \\
\hline & Judaism & 4 & 1.6 \\
\hline \multirow[t]{2}{*}{ Relationship status } & Single & 121 & 48.4 \\
\hline & In relationship & 129 & 51.6 \\
\hline
\end{tabular}

A total of 250 senior high school students took part in this study. Table 1 above shows that a good proportion of respondents, $136(54.4 \%)$ were within the age category of 16 - 19 years, and the remaining $49(19.6 \%)$ were within 12 - 15 years. It was also revealed that $129(51.6 \%)$ of the respondents were dating (relationship), and the rest $121(48.4 \%)$ were single. A good majority of the respondents, $200(80.0 \%)$ were Christians, and only $4(1.6 \%)$ were practising Judaism religion. Males constituted the dominant group with $145(58.0 \%)$, and the females were $105(42.0 \%)$.

\subsection{The Knowledge of Students on STIs}

The knowledge level of students on STIs was measured using eleven questions on STIs, and the responses were presented in frequencies and percentages using a table.

Table 2; Knowledge of Students on STIs

\begin{tabular}{lll}
\hline Variable (s) & Yes & No \\
\hline The same virus causes genital herpes as HIV & $51(20.5 \%)$ & $199(79.6 \%)$ \\
There is a cure for gonorrhea and syphilis & $215(86.0 \%)$ & $35(14.0 \%)$ \\
There is cure for HIV/AIDS & $79(31.6 \%)$ & $171(68.4 \%)$ \\
Anal sex increases the risk of STIs & $74(29.6 \%)$ & $176(70.4 \%)$ \\
Person develops sores after HIV infection & $54(21.6 \%)$ & $196(78.4 \%)$ \\
There is a cure for chlamydia & $102(40.8 \%)$ & $148(59.2 \%)$ \\
Gonorrhea and Syphilis can be seen physically & $115(46.0 \%)$ & $135(54.0 \%)$ \\
The same virus causes all known STIs & $68(27.2 \%)$ & $182(72.8 \%)$ \\
Condom prevent one from getting HIV and other STIs & $121(48.4 \%)$ & $129(51.6 \%)$ \\
There is vaccine for HIV & $97(38.8 \%)$ & $153(61.2 \%)$ \\
There is a vaccine for Hepatitis B & $115(46.0 \%)$ & $135(54.0 \%)$ \\
\hline
\end{tabular}




\section{International Journal of Multidisciplinary Studies and Innovative Research \\ Publisher: Catholic University College of Ghana \\ ISSN: 2737-7172 (0), ISSN: 2737-7180 (P) \\ DOI: $10.53075 /$ ljmsirq6547586021 \\ DOI Url: http://doi.org/10.53075/ljmsirq6547586021}

In order to determine the knowledge of the respondents' on STIs. A Series of questions were asked as indicated in the table 3 above. Participants were asked as to whether genital herpes is caused by the same virus as HIV. Out of the 250 respondents, only few (20.5\%) responded in affirmative while 10 of them representing (79.6\%) either had no idea or believed that does not cause it. With where there is a cure for gonorrhea and syphilis, $86 \%$, perceived that there is a cure whereas $14 \%$ said there is no cure. Only few, $29.6 \%$ agreed that, anal sex is more likely to increase risk of STIs whereas $70.4 \%$ said anal sex may not increase one's risk of contracting STIs. Moreover, $21.6 \%$ of the respondents believed that there is a development of sore after HIV infection whereas the majority (78.4\%) said no to that. Also, a greater number, $59.2 \%$ of the respondents said there is no cure for Chlamydia whereas, $40.8 \%$ said chlamydia has a cure. More than half (54.0\%) of the respondents perceived that gonorrhea and syphilis infections cannot be seen physically whereas the remaining, $46.0 \%$ agreed that it can be seen physically. Less than half $(27.2 \%)$ said a single virus causes all STIs, whereas the remaining $72.8 \%$ didn't believe this. A greater portion of the study population (51.6\%) said condom does not prevent STIs but $48.4 \%$ were of the view that condom use can prevent STIs. Also, $61.2 \%$ said there is vaccine for HIV whilst $38.8 \%$ said there is no vaccine for HIV. Finally, more than half (54.0\%) said there is a vaccine for Hepatitis B virus, whereas $46 \%$ said there is vaccine for Hepatitis B.

Table 3; Rating the Knowledge Level of Students

\begin{tabular}{lll}
\hline Variable (s) & Frequency & Percent \\
\hline High Knowledge & 100 & 40 \\
Low Knowledge & 150 & 60 \\
Total & 250 & 100 \\
\hline
\end{tabular}

In assessing the overall Knowledge level of the students towards STIs in this current study, eleven (11) questions were posed. Out of the 11 statements used, a "Yes" and "No" were used as the indicators for determining whether or not the students had knowledge on the concept of STIs. From the 11 statements, a score of (5-11) indicated high knowledge while a score of (0-4) indicated low knowledge. The scores were then converted to percentages. (See table 3)

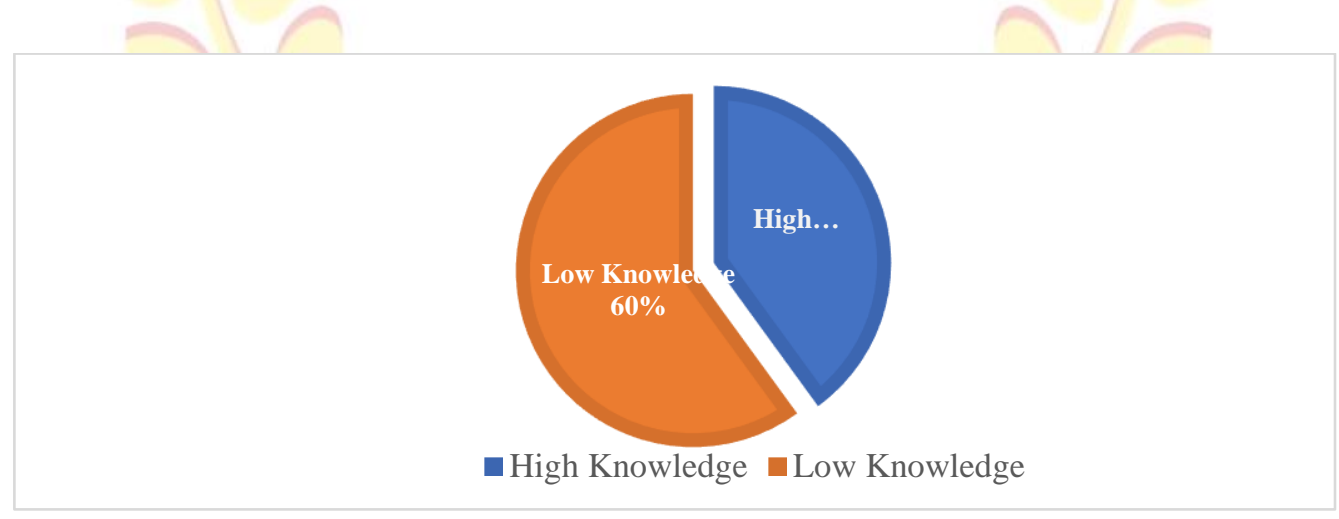

Figure 1; Respondents Overall Level of Knowledge

The results for the overall knowledge level of respondents are presented in figure 1 above. The results indicate that only $40 \%$ were found to possess high knowledge of STIs, whereas the majority of $60 \%$ had low knowledge of STIs.

\subsection{DISCUSSION OF RESULTS}

\subsection{Knowledge level of students on sexually transmitted infections}

It is an indisputable fact that knowledge and attitudes of the youth regarding STIs, including HIV/AIDS and its prevention, remains an integral aspect of the lives of the youth regarding their decision making in practising safer sex in order to eschew contracting HIV and other STIs. 


\section{International Journal of Multidisciplinary Studies and Innovative Research \\ Publisher: Catholic University College of Ghana \\ ISSN: 2737-7172 (0), ISSN: 2737-7180 (P) \\ DOI: $10.53075 /$ ljmsirq6547586021 \\ DOI Url: http://doi.org/10.53075/ljmsirq6547586021}

The study found that only 100 students (40\%) possessed high knowledge on STIs after scoring more than 5 of the eleven questions posed, whereas a good majority of 150 (60\%) possessed low knowledge on STIs for scoring less than 5 of the 11 questions asked.

In this information age where technology is the order of the day and with the ease of access to the internet one would expect these young students to possess a higher knowledge on STIs especially when they can easily get information on STIs via google and other search engines. However, the reverse is the case as the majority of the students couldn't answer simple questions on STIs rightly. Classic examples can be mentioned of when a question like "there is a cure for HIV/AIDS" was posed and sadly 79(31.6\%) answered "yes". Imagine a question like "there is a vaccine for HIV", and 97(38.8\%) answered "yes". And a lot of such wrong answers were replicated across virtually all the questions.

Some underlying factors could have accounted for this low knowledge on STIs among the respondents. Lack of sex (STI) education in our senior high schools can be one of such factors, even though students are taught integrated science as a general subject, but the curriculum does not include a typical sex education with special emphasis on sexually transmitted infections. Most students are also shy to ask their teachers questions relating to sexually transmitted infections due to the sensitive nature of it. Most parents do not also make it a point to educate their young children on sexually transmitted infections due to huge gap our society has created between the elderly and children relative to sexual matters. I must admit that parents cannot largely be blamed for this problem because most of our parents are uneducated and hence lack the requisite knowledge on sexually transmitted infections.

This low knowledge level (40\%) exhibited by respondents as observed from this current study contradicts the knowledge observation made by Norbu, Mukhia, \& Tshokey (2013) where they found $61.6 \%$ high knowledge level. It must be noted that though Norbu et al (2013), in their study found out that higher education level was directly associated with a higher level of knowledge on STI, however, the same study stressed that there was no decline in risky sexual behaviours in spite of the high knowledge on STIs.

In a similar study conducted by Ndjiembi et al. (2014) in Libreville-Gabon among senior high school students to assess their knowledge, attitudes and practices towards HIV/AIDS. The study observed that more than half of the respondents $(55.7 \%)$ had good knowledge of STIs but this current study is in sharp contrast to this observation. This current finding further corroborates GDHS (2008) report, which indicated that only $25 \%$ of young women and $33 \%$ of young men aged 15 - 24 years had ample knowledge on STIs and for that matter HIV. Therefore, there should be a deliberate conscious effort to increase the knowledge level of the youth on STIs and HIV, especially since it has no cure.

\subsection{CONCLUSIONS}

The study concludes that the majority of senior high school students had low knowledge of STIs associated with sexual risk behaviour, which is worrying.

\subsection{RECOMMENDATION}

The Ministry of Education must collaborate with the Ministry of Health to roll out adolescent health programmes in the curriculum geared towards sex and STI education. This is essential in increasing students' knowledge level on STIs in order to engender preventive and safe sex practices.

\section{ACKNOWLEDGEMENT}

We wish to express our profound gratitude to the headmaster, teachers and students of the Twene Amanfo Senior High Technical School for their unflinching support during the study. We further thank the tutorial staff of the College of Health Yamfo for their diverse efforts to make the college a hub for quality research. We importantly acknowledge Dr. Kofi Bobi Barimah and Mrs. Sandra Adelaide Hanson for their spectacular support. 


\section{REFERENCES}

Asante, K. O., Doku, N. P., \& Osafo, J. (2016). The role of condom uses self-efficacy on intended and actual condom use among university students in Ghana. Journal of Community Health, 41(1), 97-104. http://doi.org/10.1007/s10900-015-0073-6

Christiane, N. A., Roger, Z. M., Masika, J., \& Zhang, Y. (2014). HIV / AIDS prevalence , knowledge , attitudes and related behaviors among young people in Libreville, Gabon, 19(1), 59-65.

GDHS (2008). Ghana Demographic and Health Survey

GDHS (2014). Ghana Demographic and Health Survey

Norbu, K., Mukhia, S., \& Tshokey. (2013). Assessment of knowledge on sexually transmitted infections and sexual risk behaviour in two rural districts of Bhutan. BMC Public Health, 13(1), 1142.

http://doi.org/10.1186/1471-2458-13-1142

Oppong Asante K, Oti-Boadi M. HIV/AIDS knowledge among undergraduate university students: implications for health education programs in Ghana. African Health Sciences. 2013; 13(2):270-277. doi:10.4314/ ahs.v13i2.11. 